\title{
Alma mater or Science, Inc?
}

\author{
Modern universities compete not only for the best students worldwide, but also for \\ international research funds. Does commercialization threaten our universities?
}

This month sees the centenary of Imperial College London, one of Europe's leading universities. A little known fact is that Nature shares a common history with Imperial College in the form of its founding editor, Norman Lockyer, who was a professor at one of Imperial's constituting colleges. Either way, let us use this opportunity to consider what lessons can be learned from Imperial's success over the past century.

With roots dating back to the 1850 s, Imperial is part of a number of technical institutions founded during the industrialization of the west. ETH Zurich was founded in 1855, MIT in 1861 and Stanford in 1891. One of the reasons for founding these institutions during this era was to produce enough scientists to satisfy a rapidly rising demand for highly qualified engineers. This mission remains, although during the last century the scope of most of these universities has changed from a regional or national level to the international stage.

As a consequence, competition between universities for research grants has intensified, in particular as multinational companies looking for academic partners in joint ventures 'shop' for know-how worldwide. For example, when the British oil company BP was looking for an academic partner in a $\$ 500$ million research programme on biofuels, the competition was global, with US universities Berkeley and Illinois eventually winning this substantial 10-year grant.

As Berkeley's chancellor Robert Birgeneau writes in his Commentary on page 465 of this issue, the BP biofuel programme represents part of a key effort for Berkeley in creating multidisciplinary research programmes for certain strategic areas of research ${ }^{1}$. However, the award of such a huge corporate grant also met significant resistance amongst some

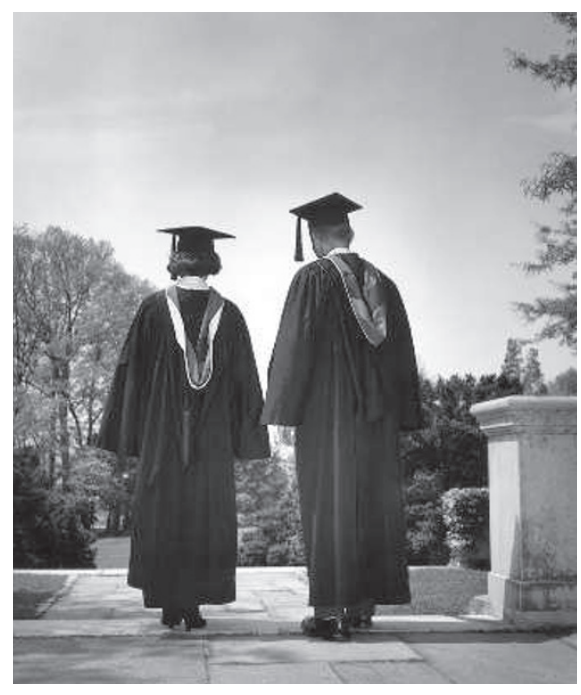

Are traditional universities on the way out?

faculty in Berkeley ${ }^{2}$ : Should there be an independent oversight committee to monitor the execution of the grant? How does public research square with corporate interests, in particular at this scale? Does it mean that the company dictates the research strategy for whole departments, and therefore does it represent a complete sell-out of academic freedom?

These questions are profound and touch the very foundation of public universities. On the other hand, basic research is very expensive, and collaboration between academia and industry makes sense for both parties. Indeed, as expressed by the rector of Imperial College, Richard Sykes, in our Interview on the occasion of the centenary (page 468), multinational companies cannot any longer afford expensive basic research - they need to rely on university collaboration ${ }^{3}$. This indeed is crucial for national economies.
Of course, universities need to be aware of the caveats. Intellectual property needs to be non-exclusive and carefully balanced with a duty to ensure that the public infrastructure used for such projects serves the interest of the wider public and not just single corporations. Corporate sponsorship on this scale should not be allowed to overwhelmingly dominate a faculty, and instead follow existing research interests of a department, not vice versa. Academic freedom needs to be preserved. Therefore, it is the duty of university administration to ensure that universities are equal partners in such ventures.

However, it would be shortsighted to use such fundamental issues to shut the door on these deals. To be successful, universities need to embrace change and need to invite corporate sponsors to their campuses. Last but not least, in many places there are even more pressing issues to solve. Cumbersome hierarchical structures need to be straightened out, interdisciplinary collaborations between academic institutions nourished and endowment funds created. It is inconceivable that in some countries universities are still kept on a short leash by rigid political structures and have little say in their own academic as well as financial matters, in the salary scales of their academics or in the selection of the students they take in.

The challenges facing modern universities are significant, and in many cases complex structural problems need to be overcome. However, in doing this we must not forget that the mission of any modern university remains to provide the best possible academic education and to nourish basic research.

\footnotetext{
References

1. Birgeneau, R. J. Nature Mater. 6, 465-467 (2007).

2. DelVecchio, R. San Francisco Chronicle (17 April 2007); available via http://tinyurl.com/36jj5e

3. Interview. Nature Mater. 6, 468-469 (2007).
} 